\title{
Abnormally High Levels of Serum a-Klotho May Result in a Poor Clinical Outcome for a 41-Year-Old Woman
}

\author{
Sagiri Taguchia, b, Miyako Funabiki ${ }^{\mathrm{a}}$, Yoshitaka Nakamura ${ }^{\mathrm{a}}$
}

\begin{abstract}
Increased levels of serum $\alpha$-klotho are beneficial for humans. However, we report a case of abnormally high levels of serum $\alpha$-klotho resulting in a poor clinical outcome for a 41-year-old woman. Her unborn child had a 47, XXY karyotype (Klinefelter syndrome). Therefore, an abnormal increase in $\alpha$-klotho is not always beneficial for humans.
\end{abstract}

Keywords: Infertility; Pregnancy; Serum $\alpha$-klotho levels

\section{Introduction}

Klotho protein was detected in 1997 [1] and since then is intensively researched. Many researchers indicate the relationship of its reduced concentration with premature aging, bone mass loss, chronic renal failure and other degenerative processes. Increases in $\alpha$-klotho levels in human serum correlate positively with the promotion of human health [2]. Furthermore, the maternal plasma concentration of $\alpha$-klotho is higher during pregnancy than in the non-pregnant state [3]. However, an association between serum $\alpha$-klotho levels and the clinical outcome of post-clinical pregnancy is controversial.

\section{Case Report}

A 41-year-old woman visited our in vitro fertilization (IVF) clinic in November 2011. Her hormone levels in the follicular phase of preimplantation were $3.0 \mathrm{mIU} / \mathrm{mL}$ for luteinizing hormone (LH), $11.1 \mathrm{mIU} / \mathrm{mL}$ for follicle stimulating hormone (FSH), and $26 \mathrm{pg} / \mathrm{mL}$ for estradiol (E2). Using ICSI, the patient experienced a clinical pregnancy in October 2013. However,

Manuscript accepted for publication September 16, 2015

aIVF Center, Oak Clinic, Osaka, Japan

${ }^{\text {b} C o r r e s p o n d i n g ~ A u t h o r: ~ S a g i r i ~ T a g u c h i, ~ I V F ~ C e n t e r, ~ O a k ~ C l i n i c, ~ 2-7-9 ~ T a m a-~}$ de-Nishi, Nishinari-ku, Osaka 557-0045, Japan.

Email: taguchi_s@oakclinic-group.com

doi: http://dx.doi.org/10.14740/jmc2299w her unborn child was diagnosed with typical Klinefelter syndrome (47, XXY karyotype) via an amniotic diagnosis, which was performed with informed consent at 17 weeks of pregnancy (Fig. 1). Furthermore, after the amniotic diagnosis, she had an abortion with informed consent. No health problems, including genetic disorders, were found in her husband or either parent.

The patient's serum $\alpha$-klotho levels were 1,971.12 \pm $201.11 \mathrm{pg} / \mathrm{mL}($ mean $\pm \mathrm{SD}$ ). Her serum $\alpha$-klotho levels were evaluated in the follicular phase of preimplantation using the human soluble $\alpha$-klotho assay kit (Takara Bio Inc., Japan) at Oak Clinic. According to a previous report [2], the serum $\alpha$-klotho levels were $562 \pm 146 \mathrm{pg} / \mathrm{mL}$ in healthy adults $(\mathrm{n}=$ 142 , mean \pm SD) at age of 20 years old or over. Furthermore, the serum $\alpha$-klotho levels were not modified by gender [2]. Moreover, the median serum $\alpha$-klotho levels in women with uncomplicated pregnancies were higher than those of nonpregnant women $(1,206(894-2,012) \mathrm{pg} / \mathrm{mL}$ in the women with uncomplicated pregnancies vs. $930(660-1,258) \mathrm{pg} / \mathrm{mL}$ in the non-pregnant women) [3]. Therefore, even in women with uncomplicated pregnancies, the median serum $\alpha$-klotho levels were 1,206 $(894-2,012) \mathrm{pg} / \mathrm{mL}$. In this regard, her serum $\alpha$-klotho levels $(1,971.12 \pm 201.11 \mathrm{pg} / \mathrm{mL})$ seemed to be very high. Her serum $\alpha$-klotho levels were significantly higher than the average $\alpha$-klotho levels in Japanese healthy adults [2] (Welch's $t$ test, $\mathrm{P}=0.006,1,971.12 \pm 201.11 \mathrm{pg} / \mathrm{mL}$ versus 562 $\pm 146 \mathrm{pg} / \mathrm{mL}[2])$.

Although she had an abortion after amniotic diagnosis, she visited the clinic again for infertility treatment and to obtain appropriate genetic counselling and supportive care.

We confirm that the work in this study was carried out in accordance with the Code of Ethics of the World Medical Association (Declaration of Helsinki). Furthermore, all of the experiments were approved by the institutional review board of Oak Clinic in Japan.

\section{Discussion}

Although increases in $\alpha$-klotho levels are beneficial for humans [2], abnormally high levels of serum $\alpha$-klotho during the follicular phase of preimplantation may result in a poor clinical outcome for a 41-year-old woman. The mechanism is unclear. However, Brownstein et al described a disorder featuring hypophosphatemic rickets and hyperparathyroidism due to a 


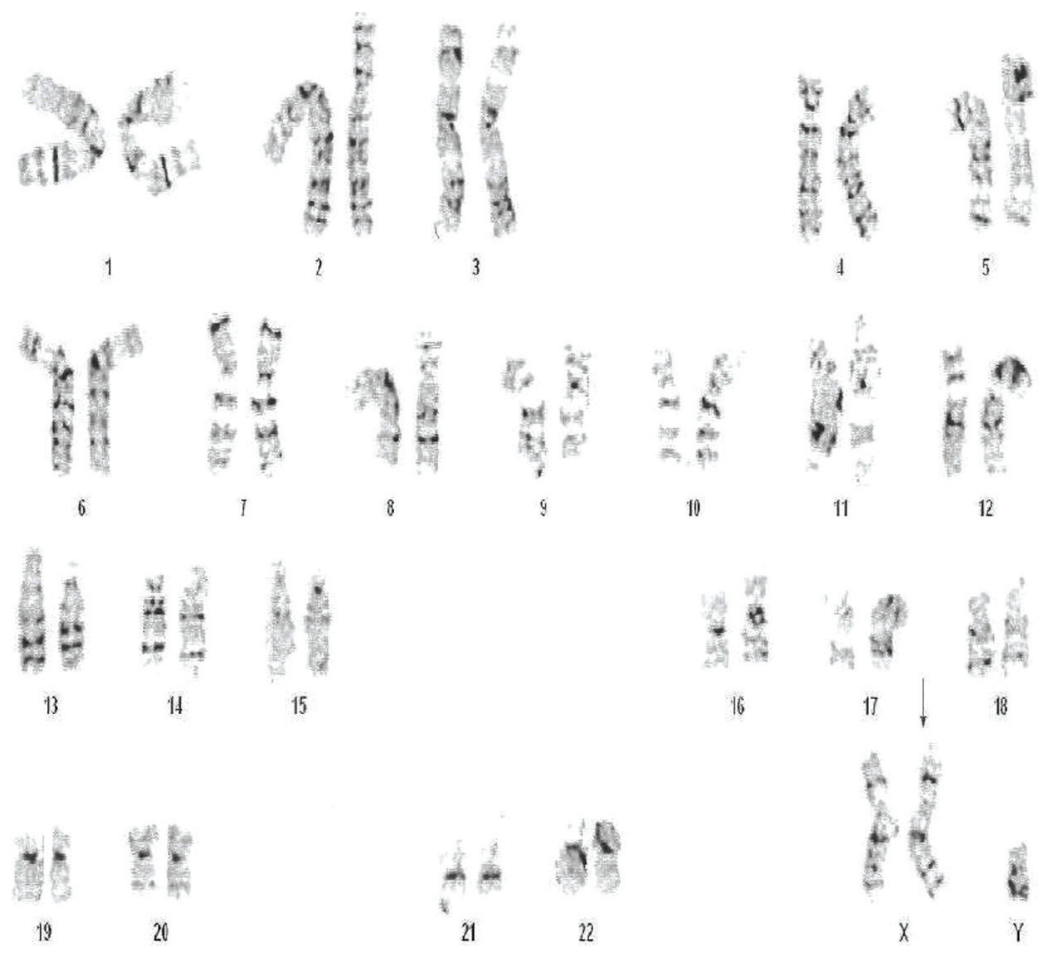

Figure 1. Chromosome analysis from the amniotic diagnosis of a 41-year-old woman.

translocation that resulted in increased levels of $\alpha$-klotho [4]. This result represents an example of a mutation that caused an increase in $\alpha$-klotho activity [4]. Therefore, an abnormal increase in $\alpha$-klotho is not always beneficial for humans. Although we speculate that the abnormally high levels of serum $\alpha$-klotho during the follicular phase of preimplantation could be directly related to the chromosomal abnormality of her unborn child, investigation of the detailed mechanism is necessary.

Considering the observations of the present study, it has been suggested that women with abnormally high levels of serum $\alpha$-klotho during the follicular phase of preimplantation that are not pregnant should be followed up carefully. However, to establish the appropriate follow-up method, prospective association studies of serum $\alpha$-klotho levels during the follicular phase of preimplantation and the clinical outcome of post-clinical pregnancy must be conducted.

\section{Acknowledgement}

We are grateful to Dr. Saji F, Ms. Amano N (data collection) and Dr. Moriguchi $\mathrm{H}$ (conception and data analyses) at Oak Clinic in Japan.

\section{Conflict of Interest}

We have no conflict of interest.

\section{Grant Support}

The present study is self-funding.

\section{References}

1. Kuro-o M, Matsumura Y, Aizawa H, Kawaguchi H, Suga T, Utsugi T, Ohyama Y, et al. Mutation of the mouse klotho gene leads to a syndrome resembling ageing. Nature. 1997;390(6655):45-51.

2. Yamazaki Y, Imura A, Urakawa I, Shimada T, Murakami J, Aono Y, Hasegawa H, et al. Establishment of sandwich ELISA for soluble alpha-Klotho measurement: Age-dependent change of soluble alpha-Klotho levels in healthy subjects. Biochem Biophys Res Commun. 2010;398(3):513-518.

3. Miranda J, Romero R, Korzeniewski SJ, Schwartz AG, Chaemsaithong P, Stampalija T, Yeo L, et al. The antiaging factor alpha-klotho during human pregnancy and its expression in pregnancies complicated by small-forgestational-age neonates and/or preeclampsia. J Matern Fetal Neonatal Med. 2014;27(5):449-457.

4. Brownstein CA, Adler F, Nelson-Williams C, Iijima J, Li $\mathrm{P}$, Imura A, Nabeshima Y, et al. A translocation causing increased alpha-klotho level results in hypophosphatemic rickets and hyperparathyroidism. Proc Natl Acad Sci U S A. 2008;105(9):3455-3460. 